ilim FUNCTIONAL

rwastame PLANT BiOLOGY

\title{
Proton and anion transport across the tonoplast vesicles in bromeliad species
}

\begin{tabular}{|r|l|}
\hline Journal: & Functional Plant Biology \\
\hline Manuscript ID & FP16293.R1 \\
\hline Manuscript Type: & Research paper \\
\hline Date Submitted by the Author: & n/a \\
\hline Complete List of Authors: & $\begin{array}{l}\text { Pereira, Paula; University of Sao Paulo, Botany } \\
\text { Smith, Andrew; University of Oxford, Dept of Plant Sciences } \\
\text { Purgatto, Eduardo; University of Sao Paulo, Department of Food and } \\
\text { Experimental Nutrition } \\
\text { Mercier, Helenice; Universidade de Sao Paulo Instituto de Biociencias, } \\
\text { Departamento de Botânica }\end{array}$ \\
\hline Keyword: & Bromeliacae, CAM plants, Malate, Proton pump, Vacuoles \\
\hline & \\
\hline
\end{tabular}

\section{SCHOLARONE}

Manuscripts 
1 Helenice Mercier

2 e-mail: $\underline{\text { hmercier@usp.br }}$

3 Phone number: (55) (11) 30918066

$4 \quad$ FAX number: (55) (11) 30917547

5 Address: Department of Botany, Institute of Biosciences, University of São Paulo,

6 CEP 05508-090, São Paulo, SP, Brazil

7

8

9

10

11

12

13

14

15

16

17

18

19

20

21

22

23 
1 Title: Proton and anion transport across the tonoplast vesicles in bromeliad species

2 Running head: Proton and anion transport in bromeliads

3 Paula Natália Pereira ${ }^{\mathbf{a}}$, James Andrew Charles Smith $^{\mathrm{b}}$, Eduardo Purgatto ${ }^{\mathrm{c}}$ and

4 Helenice Mercier $^{a}$

5 a Department of Botany, Institute of Biosciences, University of São Paulo, CEP 05508-

6 090, São Paulo, SP, Brazil.

$7 \quad{ }^{b}$ Department of Plant Sciences, University of Oxford, Oxford, OX1 3RB, UK.

$8{ }^{\mathrm{c}}$ Department of Food and Experimental Nutrition, Faculty of Pharmaceutical Sciences,

9 University of São Paulo, CEP 05422-970 São Paulo, SP, Brazil. 


\section{Abstract}

2 Crassulacean acid metabolism (CAM) is one of the key innovations in the Neotropical

3 family Bromeliaceae that has enabled many of its species to occupy seasonally water-

4 limited terrestrial environments or microclimatically arid epiphytic niches. However,

5 the relationship between CAM activity and the transport processes responsible for

6 vacuolar organic-acid accumulation at night has not been systematically explored in this

7 family. In the present investigation, ATP- and PPi-dependent proton transport rates

8 were studied in tonoplast membrane vesicles isolated from leaves of six CAM and one

$9 \mathrm{C}_{3}$ species of bromeliads. A consistent feature of these species was the high activity of the tonoplast ATP-driven $\mathrm{H}^{+}$pump which, averaged across the seven species tested, showed a higher specific activity than the tonoplast PPi-driven $\mathrm{H}^{+}$pump. For all CAM species, the rate of ATP-dependent proton transport into the tonoplast vesicles was strongly influenced by the nature of the balancing organic-acid anion, which displayed the following order of effectiveness: fumarate $>$ malate $>$ citrate. Measurements of leaf organic-acid content in six CAM bromeliads at dusk and dawn showed that nocturnal accumulation of malate exceeded citrate by a factor of about 2.4-20.0 fold in five from six bromeliad species used in this study, demonstrating a close correlation between the CAM rhythm and the intrinsic properties of the vacuolar membrane across which these organic acids are transported.

Additional keywords: Bromeliaceae, CAM plants, malate, proton pump, vacuoles.

\section{Introduction}

The Neotropical family Bromeliaceae represents a highly diverse group of vascular plants containing well over 3000 species. Members of this family exhibit some distinctive innovations associated with the wide variety of habitats they occupy (Benzing 1980, 2000; Smith et al. 1986; Smith 1989; Givnish et al. 2011; Crayn et al. 2015). One key innovation in bromeliads is the absorptive epidermal trichomes, which are responsible for uptake of water and nutrients through the leaf surface in epiphytic species (Mez 1904; Smith and Till 1998). Another is the presence of a 'tank' structure (phytotelm) formed by the overlapping basal portions of the rosulate leaves. This

32 structure is important because it collects the detritus and water that is ultimately 
1 absorbed by the epidermal trichomes, which are present at higher density towards the

2 basal compared with apical portion of the leaves, and which in the more extreme

3 'atmospheric' epiphytic forms in this family cover almost the entire shoot surface. The

4 absorptive epidermal trichome and water-impounding tank are very likely two of the

5 key adaptations that aided evolution of the epiphytic life-forms in Bromeliaceae

6 (Medina 1974; Benzing 1980, 2000; Smith 1989; Givnish et al. 1997).

Crassulacean acid metabolism (CAM) is another physiological innovation

8 found in many species of Bromeliaceae (Coutinho 1963; Medina 1974; Crayn et al.

9 2004). This mode of photosynthesis is characterized by nocturnal $\mathrm{CO}_{2}$ fixation via the

10 enzyme phosphoenolpyruvate carboxylase (PEPC), which represents a highly water-

11 conserving photosynthetic pathway since it allows stomata to remain closed for much of

12 the daytime (Kluge and Ting 1978; Winter and Smith 1996; Silvera and Lasso 2016). In

13 a recent survey of Bromeliaceae encompassing nearly two-thirds of the family, Crayn et

14 al. (2015) found that $43 \%$ of the species sampled showed carbon-isotope ratios indicative of obligate CAM photosynthesis. Among the eight constituent subfamilies there are five that contain CAM species, although in very different proportions. For example, from 792 sampled species in subfamily Tillandsioideae, only $28 \%$ showed $\delta^{13} \mathrm{C}$ values indicative of obligate CAM, all of which were in the genus Tillandsia, with the remaining genera, including Vriesea, Werauhia, Catopsis, Guzmania, Alcantarea and Racinaea, showing $\mathrm{C}_{3}$ photosynthesis. In contrast, in subfamily Bromelioideae, the majority of genera (including $90 \%$ of the 499 sampled species) exhibited the CAM pathway, with only a few genera, namely Fernseea, Fascicularia, Greigia, Lapanthus and Ochagavia, showing $\mathrm{C}_{3}$ photosynthesis (Crayn et al. 2015).

Over the years, numerous physiological and biochemical studies have been conducted on the terrestrial CAM bromeliad Ananas comosus (L.) Merr., the pineapple, which is one of the best-known species in the family because of its economic importance (Neales et al. 1968; Martin 1994; Ming et al. 2015). Methods for the isolation of vacuolar membrane have been reported for this species, and the $\mathrm{H}^{+}$-ATPase and $\mathrm{H}^{+}$-inorganic pyrophosphatase (PPiase) characteristic of the tonoplast have been partially characterized (Chen and Nose 2000; McRae et al. 2002). The tonoplast of pineapple also possesses a relatively low-affinity sucrose transporter, which is presumed to mediate transport of sucrose from the cytosol into the vacuole during the daytime (McRae et al. 2002; Ming et al. 2015). However, little has been studied concerning the 
1 process of organic acid transport across the vacuolar membrane in this species or other

2 members from the family Bromeliaceae. White and Smith (1989) found in Kalanchoë

3 daigremontiana Hamet et Perrier de la Bâthie, a constitutive CAM plant, that the

4 highest rates of ATP- and PPi-dependent $\mathrm{H}^{+}$transport across the vacuolar membrane

5 could be observed in the presence of malate and certain other four-carbon dicarboxylate

6 anions. This was subsequently shown to be attributable to a distinctive inward-

7 rectifying anion channel (Hafke et al. 2003), which seems to be an inherent feature of

8 the vacuolar membranes of CAM plants. In studies with the inducible CAM plant

9 Mesembryanthemum crystallinum L., it has been shown that rates of ATP-dependent $\mathrm{H}^{+}$

10 transport at the vacuolar membrane are higher in plants in the CAM mode compared

11 with the $\mathrm{C}_{3}$ mode, and that CAM induction by salt stress appeared to be associated with

12 increased permeability of the tonoplast membrane to malate (Struve and Lüttge 1987;

13 Barkla et al. 1995; Lüttge et al. 2000).

Although studies have been done on proton transport and the permeability of vacuolar membranes for malate and fumarate in CAM constitutive plants, no studies have been conducted to check this transport within different CAM species from the same family or even from the same subfamily. In addition, no studies have been performed to evaluate the difference in the vacuolar transport between CAM plants kept in the same growth conditions. Based on this scenario, this study aims to evaluate the ATP-driven $\mathrm{H}^{+}$pump at the tonoplast compared with the PPi-driven $\mathrm{H}^{+}$pump, and measure the organic acids, malate and citrate, accumulated during the night in six bromeliad species, all of which perform CAM, from the subfamilies Bromelioideae or Tillandsioideae (Fig. 1). All results were obtained through a combination of biochemical approaches. This study also examines the possible correlation between nocturnal malate and citrate accumulation, their transport across the tonoplast, and the degree of CAM expression among bromeliad species kept in the same environmental conditions. Finally, this study evaluates the relative activities of the tonoplast ATPase and PPiase for each bromeliad species with respect to proton pumping into isolated membrane vesicles, as well as the order of effectiveness of fumarate, malate and citrate as balancing permeant anions in sustaining the activity of these electrogenic pumps. 
1 Adult plants of Aechmea nudicaulis (L.) Griseb., Ananas comosus (L.) Merr. var.

2 ananassoides, Billbergia pyramidalis (Sims) Lindl., Nidularium billbergioides (Schult.

3 \& Schult.f.) L.B.Sm., Tillandsia pohliana Mez, Tillandsia usneoides (L.) L. and Vriesea

$4 \quad$ sucrei L.B.Sm \& Read (used for comparison as a species that performs $\mathrm{C}_{3}$

5 photosynthesis) (Fig. 1) were collected in the Institute of Botany of São Paulo, and were

6 then transferred to a controlled environment growth chamber, under a photosynthetic

7 flux density (PFD) of about $200 \mu \mathrm{mol} \mathrm{m}^{-2} \mathrm{~s}^{-1}$ of photosynthetic active radiation

8 (measured at the surfaces of the uppermost leaves), a $12 \mathrm{~h}$ photoperiod, a day/night air

9 temperature of $25 / 20^{\circ} \mathrm{C}$, and a day/night relative humidity of $60 / 70 \%$. Plants were

10 cultivated in pots containing fine sand, with one plant per pot. Over 10 days of

11 acclimation, all plants were watered with distilled water on a daily basis. After this

12 period, about 8 to 12 fully developed leaves, or stem internodes in the case of $T$. usneoides, were collected for the biochemical assays.

\section{Tonoplast isolation}

Tissue was harvested from plants in the controlled environment chambers 1.0 to $1.5 \mathrm{~h}$ after commencement of the light period. Tonoplast fractions from the mesophyll tissue were isolated according to the method of White \& Smith (1989) and McRae et al. (2002) with minor modifications. The leaf tips and margins were removed from excised leaves using a razor blade, and sections of leaf lamina or stem totaling approximately 80 $\mathrm{g}$ fresh mass were suspended in $250 \mathrm{~mL}$ of ice-cold extraction buffer containing the following: $450 \mathrm{mM}$ mannitol, $3.0 \mathrm{mM} \mathrm{MgSO}$, $2.0 \mathrm{mM}$ ethylenediaminetetraacetic acid disodium salt (EDTA), $10 \mathrm{mM}$ DL-dithiothreitol (DTT), 1.0\% (w/v) polyvinylpyrrolidone (PVP-40), 0.5\% (w/v) bovine serum albumin, $100 \mathrm{mM}$ tris(hydroxymethyl)aminomethane (Trizma ${ }^{\circledR}$ base, adjusted to $\mathrm{pH} 8.0$ with $\mathrm{HCl}$ ), $1 \mathrm{mM}$ phenylmethysulphonyl fluoride, 1.1 M glycerol, $0.5 \mathrm{mM}$ 3,5-di-tert-4butylhydroxytoluene, $25.19 \mathrm{mM}$ potassium disulfite and $1.0 \mathrm{mM}$ benzamidine hydrochloride. After precooling, the tissue was homogenized in a commercial blender and the homogenate filtered through two layers of cheesecloth and then centrifuged at $18000 \times g$ for $20 \mathrm{~min}$. The resulting supernatant was centrifuged at $80000 \times g$ for 60 min. The resulting pellet was layered over a $25 \%(\mathrm{w} / \mathrm{v})$ sucrose cushion containing 1.1 M glycerol, 1.0 mM disodium EDTA, $10 \mathrm{mM}$ Tricine $(N$ [tris(hydroxymethyl)methyl]glycine), adjusted to $\mathrm{pH} 8.0$ with BTP (1,3- 
1 bis[tris(hydroxymethyl)methylamino]propane), and 2.0 mM DTT. The gradients were

2 centrifuged at $100000 \times \mathrm{g}$ for $70 \mathrm{~min}$, after which tonoplast vesicles were removed

3 from the interface using a Pasteur pipette. Vesicles were then pelleted at $100000 \times g$ for

$450 \mathrm{~min}$ and finally resuspended in the same buffer as the first pellet. All steps were

5 performed at $4^{\circ} \mathrm{C}$. Preparations were stored at $-80^{\circ} \mathrm{C}$ until required.

Measurement of vesicle acidification

7 Rates of intravesicular acidification on energization of the tonoplast $\mathrm{H}^{+}$-ATPase or $\mathrm{H}^{+}$-

8 PPiase were determined according to the method described by White \& Smith (1989)

9 with minor modification. Initial rates of $\mathrm{H}^{+}$transport at $25^{\circ} \mathrm{C}$ were determined from the initial rates of fluorescence quenching upon the addition of $3.0 \mathrm{mM}$ Tris-ATP or 500 $\mu \mathrm{M} \mathrm{Na}{ }_{4} \mathrm{PPi}$ to the reaction medium. For assays of ATP-dependent $\mathrm{H}^{+}$transport, the reaction medium contained approx. $2-9 \mu \mathrm{g}$ protein, $3.0 \mu \mathrm{M}$ quinacrine (6-chloro-9- $\{[4-$ (diethylamino)-1-methylbutyl]amino \}-2-methoxyacridine dihydrochloride), $6.0 \mathrm{mM}$ $\mathrm{MgSO}_{4}, 0.3 \mathrm{mM}$ disodium EDTA, $150 \mathrm{mM}$ mannitol and $25 \mathrm{mM}$ BTP buffered to $\mathrm{pH}$ 8.0 with Mes (2-( $N$-morpholino)ethansulphonic acid). For measurements of PPidependent $\mathrm{H}^{+}$transport, the reaction medium was identical except that the $\mathrm{MgSO}_{4}$ concentration was increased to $7.5 \mathrm{mM}$ and the medium also contained $100 \mathrm{mM}$ K-Mes. Permeant anions to be tested were present at $50 \mathrm{mM}$ (supplied as fumaric acid, malic acid, or citric acid, and buffered to $\mathrm{pH} 8.0$ with BTP). Inhibitors tested (final concentrations) were $50 \mathrm{mM}$ potassium nitrate (inhibitor of vacuolar $\mathrm{H}^{+}$-ATPase), 100 $\mu \mathrm{M}$ sodium orthovanadate (inhibitor of plasma membrane $\mathrm{H}^{+}$-ATPase), $100 \mu \mathrm{M}$ sodium azide (inhibitor of mitochondrial ATP synthase), and $2.0 \mathrm{mM}$ ammonium sulphate (uncoupler of transmembrane $\mathrm{pH}$ gradients). Fluorescence quenching was measured using a model LS-55 luminescence spectrometer (Llantrisant, UK) with excitation at $422 \mathrm{~nm}$ and emission at $495 \mathrm{~nm}$, both with a slit width of $5 \mathrm{~nm}$.

Protein determination

Protein concentration was measured according to Bradford (1976), using bovine serum albumin as the standard.

Organic acid quantification 
1 Malate and citrate in tissue extracts were determined by HPLC in a chromatographic

2 system (Hewlett-Packard $\AA$, series 110, Waldbronn, Germany) equipped with a

3 Supelcogel C-610H $(30 \mathrm{~cm} \times 7.8 \mathrm{~mm})$ column $\left(\right.$ at $\left.30^{\circ} \mathrm{C}\right)$ and a diode-array detector $(210$

$4 \mathrm{~nm}$, for acid analysis) according to the method described by Amorós et al. (2003) and

5 Pereira et al. (2013). All measurements were made in triplicate, and the results are

6 expressed in dry weight basis (DW).

$7 \quad$ Statistical analysis

8 All data are presented as mean values \pm standard deviation (s.d.). Significant differences

9 among the bromeliad species or treatments were determined using the Tukey-Kramer test at $P<0.05$. Differences between treatments with two inhibitors in the same species were evaluated using Student's $t$-test at $P<0.05$.

\section{Results}

Proton transport rates in the presence of inhibitors of vacuolar or non-vacuolar ATPases

Initially, proton transport rates were tested using quinacrine fluorescence-quenching to assay rates of acidification of isolated tonoplast vesicles in the presence of specific inhibitors of non-vacuolar ATPases $\left(\mathrm{NaN}_{3}\right.$ plus $\left.\mathrm{Na}_{3} \mathrm{VO}_{4}\right)$ or in the presence of an inhibitor of the vacuolar $\mathrm{H}^{+}$-ATPase $\left(\mathrm{KNO}_{3}\right)$, in order to determine the relative contribution of different membranes to the ATP-dependent $\mathrm{H}^{+}$transport rates in preparations from each bromeliad species. As shown in Table 1, $\mathrm{KNO}_{3}$ caused a significantly greater inhibition of ATP-dependent proton transport than $\operatorname{did} \mathrm{NaN}_{3}$ plus $\mathrm{Na}_{3} \mathrm{VO}_{4}$ for tonoplast preparations from all seven bromeliad species tested. In Ananas comosus, Tillandsia usneoides and Vriesea sucrei, the degree of inhibition by $\mathrm{KNO}_{3}$ showed that the majority (74-88\%) of ATP-dependent proton pumping was driven by the vacuolar $\mathrm{H}^{+}$-ATPase than by $\mathrm{NaN}_{3}+\mathrm{Na}_{3} \mathrm{VO}_{4}$. In tonoplast preparations from Aechmea nudicaulis, Billbergia pyramidalis, Nidularium billbergioides and T. pohliana, the inhibition of ATP-dependent proton pumping by $\mathrm{KNO}_{3}$ was somewhat less (42$47 \%$ ), but was still at least twice the degree of inhibition caused by $\mathrm{NaN}_{3}+\mathrm{Na}_{3} \mathrm{VO}_{4}$, suggesting that in all species the predominant fraction of ATP-driven proton transport was attributable to the activity of the vacuolar $\mathrm{H}^{+}$-ATPase. 
2 ATP-dependent proton transport rates

3 Experiments were next conducted to investigate the relative activities of ATP- and PPi-

4 dependent proton transport in the tonoplast vesicle fractions prepared from the seven

5 species of bromeliads.

For all species tested, the initial rates of proton transport into the membrane

7 vesicles were monitored by quinacrine-fluorescence quenching following addition of

8 ATP or PPi in the presence of three different anions (fumarate ${ }^{2-}$, malate ${ }^{2-}$, or citrate ${ }^{3-}$ )

9 (Supplementary Figures 1 and 2). Recovery of quinacrine fluorescence to the level

10 observed immediately prior to the addition of ATP or PPi occurred after adding $2 \mathrm{mM}$

$11 \mathrm{NH}_{4}{ }^{+}$as an uncoupler of $\mathrm{pH}$ gradients (after 400-800 s, depending on the species),

12 demonstrating that the fluorescence quenching was entirely attributable to the

13 acidification of the vesicle interior (Supplementary Figure 1A).

In all of the experiments, fumarate supported the highest rates of vesicle acidification in tonoplast vesicles from all seven CAM bromeliad species (Table 2; Supplementary Figures 1 and 2). B. pyramidalis showed the highest rate of ATPdependent proton transport, in the presence of fumarate as a charge-balancing anion (achieving a rate of approximately $3000 \%$ relative fluorescence quench $\mathrm{min}^{-1} \mathrm{mg}$ protein $^{-1}$, after subtracting the control value in the absence of any added anion), followed by A. comosus, A. nudicaulis, N. billbergioides, T. pohliana and T. usneoides (Table 2). For B. pyramidalis, the rate of ATP-dependent proton transport in the presence of fumarate was about 13 times higher than that of T. usneoides (Table 2). Malate and citrate as charge-balancing anions supported considerably lower rates of ATP-dependent proton transport than fumarate, but the relative rates of proton transport showed a similar trend across the seven species (Table 2). Thus, the order of effectiveness of the three organic-acid anions in supporting ATP-dependent proton transport was fumarate $>$ malate $>$ citrate in the six CAM species.

\section{PPi-dependent proton transport rates}

In contrast to the ATP-dependent proton transport, rates of PPi-dependent $\mathrm{H}^{+}$transport into the isolated tonoplast vesicles were considerably lower and did not show such clear trends with respect to species or anion-dependence. Once again, the highest rate of PPidependent proton transport in the presence of fumarate was observed for B. pyramidalis, 
1 and the lowest for T. usneoides (Table 3), but this maximum rate for B. pyramidalis was

2 4.2-fold lower than the rate of ATP-dependent proton transport observed in the same

3 species (cf. Table 2). In general, the rates of PPi-dependent vesicle acidification were

4 not significantly higher in the presence of fumarate than they were for malate, except in

5 the case of T. pohliana (Table 3). T. usneoides, as well as showing the lowest rates of

6 PPi-dependent vesicle acidification, was anomalous in showing relatively high rates of

7 proton transport in the presence of citrate, or even without added organic-acid anion

8 (Table 3). Thus, the order of effectiveness of the anions in supporting PPi-dependent

9 proton transport was fumarate $\approx$ malate $>$ citrate for $A$. nudicaulis and $N$. billbergioides,

10 fumarate $>$ malate $>$ citrate for $A$. comosus and B. pyramidalis, fumarate $>$ citrate $>$

11 malate for T. pohliana, and citrate $>$ fumarate $\approx$ malate for T. usneoides.

12

\section{Nocturnal malate and citrate accumulation}

To relate the transport properties of the tonoplast membrane to patterns of organic-acid metabolism occurring during the CAM cycle, nocturnal accumulation of malate and citrate was measured in the leaves (and internodes of T. usneoides) of the six CAM bromeliad species included in this study (Fig. 2). All CAM species showed a greater nocturnal accumulation of malate compared with citrate when averaged across the six species. B. pyramidalis showed the highest nocturnal malate accumulation, followed by A. nudicaulis, A. comosus and N. billbergioides (Fig 2A). A. comosus and $N$. billbergioides, followed by $B$. pyramidalis, were the species that showed the greatest citrate accumulation during the dark period (Fig. 2B). As expected, V. sucrei, a $\mathrm{C}_{3}$ species, did not accumulate any malate or citrate at night, but a small amount of diurnal malate accumulation was observed, as is often found in $\mathrm{C}_{3}$ plants (Fig. 2).

\section{Discussion}

Numerous studies have been undertaken to evaluate CAM expression and its ecological significance in Bromeliaceae, which represents a particularly diverse family of angiosperms. For example, Crayn et al. (2015) used stable carbon-isotope ratios to investigate the photosynthetic pathways in 1893 bromeliad species covering nearly twothirds of the family. At a biochemical level, PEPC activity, combined with other methods, was used to monitor CAM induction in the epiphytic bromeliad Guzmania 
monostachia (L.) Rusby ex Mez (Pereira et al. 2013). At the subcellular level, although there have been many studies of ATP-and PPi-dependent proton $\left(\mathrm{H}^{+}\right)$transport in tonoplast vesicles of CAM species, only a few have investigated the intrinsic relationship between CAM photosynthesis and $\mathrm{H}^{+}$transport rates at the vacuolar membrane (White and Smith 1989, 1992; Barkla et al. 1995; McRae et al. 2002). Moreover, only one study has documented proton and sucrose transport rates across the tonoplast in a bromeliad species, Ananas comosus (McRae et al. 2002). Thus, in the present study we compared ATP- and PPi-dependent $\mathrm{H}^{+}$transport across the vacuolar membrane, and their dependence on organic-acid anions capable of providing charge balance, in tonoplast vesicles isolated from six species of CAM bromeliads (Aechmea nudicaulis, Ananas comosus, Billbergia pyramidalis, Nidularium billbergioides, Tillandsia pohliana and T. usneoides) and one $\mathrm{C}_{3}$ species (Vriesea sucrei) used as a control.

The ATP-dependent proton transport rates assayed in the presence of specific inhibitors of non-vacuolar ATPases $\left(\mathrm{NaN}_{3}\right.$ plus $\left.\mathrm{Na}_{3} \mathrm{VO}_{4}\right)$ or of $\mathrm{KNO}_{3}$ as an inhibitor of the vacuolar $\mathrm{H}^{+}$-ATPase showed that the majority of the inhibitor-sensitive ATPdependent proton pumping observed in these fractions was attributable to the vacuolar membrane (Table 1). The contribution from other membranes to ATP-dependent proton pumping in this fraction was evidently rather minor, although this varied in extent across the seven bromeliad species used in this study. McRae et al. (2000) also observed in experiments with a crude microsomal membrane fraction isolated from leaves of Ananas comosus that more than $90 \%$ of the observed ATP-dependent proton transport activity could be attributed to the vacuolar $\mathrm{H}^{+}$-ATPase on the basis of its inhibitor sensitivity. Even if these membrane preparations contain variable amounts of non-tonoplast membrane, it appears that the propensity of the tonoplast to form wellsealed, transport-competent vesicles (White and Smith 1989; McRae et al. 2002) results in the major part of the ATP-dependent proton transport observed in these preparations reflecting the activity of the vacuolar $\mathrm{H}^{+}$-ATPase.

Similar to the characteristics observed for the tonoplast of the CAM plant Kalanchoë daigremontiana (White and Smith 1989), the rates of ATP-dependent proton transport recorded here for the bromeliad tonoplast preparations in the presence of different organic-acid anions as charge-balancing anions indicated a greater permeability of the tonoplast for fumarate relative to malate and citrate. In contrast to $K$. 
1 daigremontiana, however, in which rates of ATP- and PPi-dependent $\mathrm{H}^{+}$transport

2 across the tonoplast are reasonably similar, in all of the bromeliad species studied the

3 ATP-dependent rates of proton transport were considerably higher than the PPi-

4 dependent rates for the six CAM bromeliad species (Tables 2 and 3). A similar

5 predominance of the tonoplast ATPase was observed in assays of the hydrolytic

6 activities of the vacuolar $\mathrm{H}^{+}$-ATPase and $\mathrm{H}^{+}$-PPiase in membrane preparations from

7 Ananas comosus (Chen and Nose 2000; McRae et al. 2002). A possible explanation for

8 this bias in favour of the tonoplast $\mathrm{H}^{+}$-ATPase over the $\mathrm{H}^{+}$-PPiase in bromeliads might

9 be connected with the high activity of pyrophosphate-dependent 6-phosphofructokinase

10 (PPi-PFK) in bromeliads, as first described in Ananas comosus (Carnal and Black

11 1983). The standard ATP-dependent phosphofructokinase (PFK) is responsible for

12 catalyzing the conversion of fructose 6-phosphate to fructose 1,6-biphosphate in

13 glycolysis (Pollack and Williams 1986), but it appears that in plants there are two

14 alternative enzymes for this step in glycolysis (Carnal and Black 1983; Mertens 1991;

15 Alves et al. 2001). Carnal and Black (1983) reported that angiosperms with PPi-PFK activities 4 to 70 times higher than ATP-PFK tend to be succulent and exhibit CAM photosynthesis. These same authors showed in A. comosus that PPi-PFK activity, but not ATP-PFK activity, would be sufficient to support the rate of glycolytic carbohydrate processing required for acid accumulation during the night in this CAM bromeliad species (Carnal and Black 1989). Therefore, it is possible that a relatively low activity of the tonoplast $\mathrm{H}^{+}$-PPiase in bromeliads helps to avoid competition for substrate with PPi-PFK, which is required to catalyse high rates of glycolytic breakdown of storage carbohydrate at night (Carnal and Black 1989; Holtum et al. 2005). not consider the rates of ATP- and PPi-dependent $\mathrm{H}^{+}$transport observed in control solutions in the absence of added anions (White and Smith 1989; White et al. 1990; Bettey and Smith 1993; Lüttge et al. 2000; Lüttge 2000). The rates of proton transport in the absence of supplementary anions were also not characterized in Mesembryanthemum crystallinum (Barkla et al. 1995) or in A. comosus (McRae et al. 2002). In contrast, in the present study it was observed that significant rates of ATPand PPi-dependent proton transport occurred into tonoplast vesicles of all the bromeliad species in the absence of fumarate, malate and citrate anions. Also, in the majority of the species, the rate of ATP- and PPi-dependent $\mathrm{H}^{+}$transport in the control (no added 
anion) was higher than in the presence of citrate (this anion was also not tested in most of the studies previously described). This result implies that the tonoplast membrane of bromeliads may exhibit a relatively high background conductance to some other permeant ion, although the ions involved in providing charge balance under these conditions could not be positively identified. Nevertheless, the considerably higher rates of ATP-dependent $\mathrm{H}^{+}$transport, in particular, that are observed in the presence of fumarate and malate implies that the these anions represent the most physiologically important permeant ions involved in transport across the tonoplast in bromeliads.

Besides proton transport into the vacuole, many studies have quantified the accumulation of organic acids, mainly malate and citrate, during the dark period in CAM plants as a measure of the degree of CAM activity (Maxwell et al. 1994; Pereira et al. 2013). Based on both ATP- and PPi-dependent vacuolar proton transport and the magnitude of nocturnal malate and citrate accumulation, we demonstrated the highest degree of CAM activity in B. pyramidalis, with the lowest recorded in T. usneoides. On the other hand, as expected, $V$. sucrei, used as a $\mathrm{C}_{3}$ species as a control in these experiments, revealed a diurnal malate accumulation as well as low rates of proton transport into the vacuole, a characteristic response of $\mathrm{C}_{3}$ species. For all six CAM species, $\Delta$ malate values were considerably higher than $\Delta$ citrate values (Fig. 2): the ratio averaged between $\Delta$ malate and $\Delta$ citrate was from 2.4 to 20.0 -fold depending on five of the CAM bromeliad species used in this study. For example, A. nudicaulis presented an average between $\Delta$ malate and $\Delta$ citrate of 20.0 -fold, while $A$. comosus showed an average between $\Delta$ malate and $\Delta$ citrate of 2.4 -fold. In addition, these data reveal a correlation between the accumulation of malate and citrate during the night and the rates of ATP- and PPi-dependent proton transport observed in the presence of malate or citrate anions. The quinacrine fluorescence-quenching experiments performed for all CAM species in this study showed that the permeability of the tonoplast membrane for malate appears to be consistently higher than its permeability for citrate. This result correlates well with the higher nocturnal malate accumulation in the vacuole compared with a citrate accumulation.

In summary, this study has compared ATP- and PPi-dependent proton transport in tonoplast vesicles of one $\mathrm{C}_{3}$ and six CAM bromeliad species from two subfamilies, Bromelioideae and Tillandsioideae. All the bromeliad species showed much higher rates of ATP-dependent than PPi-dependent rates of proton transport into the tonoplast 
1 vesicles. Species from the subfamily Bromelioideae exhibited a higher accumulation of

2 organic acids during the night and also a higher ATP-dependent proton transport rate

3 compared with members of the subfamily Tillandsioideae. In addition, this study

4 demonstrated the order of effectiveness of different organic-acid anions in providing

5 charge balance for ATP-dependent $\mathrm{H}^{+}$transport was fumarate $>$malate $>$citrate in the

6 six CAM bromeliad species, whereas rates of PPi-dependent $\mathrm{H}^{+}$transport were low

7 irrespective of the balancing anion present. Finally, the average rate of nocturnal malate

8 accumulation in the six CAM bromeliad species studied was five times greater than the

9 citrate accumulation, which closely reflected the relative permeability of the tonoplast to

10 these anions as shown by the ATP-dependent rates of $\mathrm{H}^{+}$transport across the vacuolar

11 membrane.

\section{Acknowledgements}

The authors acknowledge the Institute of Botany of São Paulo for supplying the plants used in this study. We also thank Coordenação de Amparo a Pesquisa do Estado de São Paulo (CAPES) (99999.001109/2014-06) for the scholarship awarded to Paula Natália Pereira, Fundação de Amparo à Pesquisa do Estado de São Paulo (FAPESP) (2011/50637-0) and Conselho Nacional de Desenvolvimento Científico e Tecnológico (CNPq) (309504/2014-7) for their support to Helenice Mercier and the Biotechnology and Biological Sciences Research Council (U.K.) for a Sparking Impact Award to J.A.C. Smith.

\section{References}

Alves AMCR, Euverink GJW, Santos H, Dijkhuizen L (2001) Different physiological roles of ATP- and $\mathrm{PP}_{\mathrm{i}}$-dependent phosphofructokinase isoenzymes in the methylotrophic actinomycete Amycolatopsis methanolica. Journal of Bacteriology 183: $7231-7240$.

Amorós A, Zapata P, Pretel MT, Botella MA, Serrano M (2003) Physico-chemical and physiological changes during fruit development and ripening of five loquat (Eriobotrya japonica Lindl.) cultivars. Food Science and Technology International 9, 43-51. 
1 Barkla BJ, Zingarelli L, Blumwald E, Smith JAC (1995) Tonoplast $\mathrm{Na}^{+} / \mathrm{H}^{+}$antiport activity and its energization by the vacuolar $\mathrm{H}^{+}$-ATPase in the halophytic plant Mesembryanthemum crystallinum L. Plant Physiology 109, 549-556.

Benzing DH (1980) 'The biology of the bromeliads.' (Mad River Press: Eureka, California, USA)

Benzing DH (2000) 'Bromeliaceae: profile of an adaptive radiation.' (Cambridge University Press: Cambridge)

Bettey M, Smith JAC (1993) Dicarboxylate transport at the vacuolar membrane of the CAM plant Kalanchoë daigremontiana: sensitivity to protein-modifying and sulphydryl reagents. Biochimica et Biophysica Acta 1152, 270-279.

Bradford MM (1976) A rapid and sensitive method for the quantitation of microgram quantities of protein utilizing the principle of protein dye binding. Analytical Biochemistry 72, 248-254.

Carnal NW, Black CC (1983) Phosphofructokinase activities in photosynthetic organisms. The occurrence of pyrophosphate-dependent 6-phosphofructokinase in plants and algae. Plant Physiology 71, 150-155.

Carnal NW, Black CC (1989) Soluble sugars as the carbohydrate reserve for CAM in pineapple leaves. Implications for the role of pyrophosphate:6-phosphofructokinase in glycolysis. Plant Physiology 90, 91-100.

Ceusters J, Borland AM, Londers E, Verdoodt V, Godts C, De Proft MP (2008) Diel shifts in carboxylation pathway and metabolite dynamics in the CAM bromeliad Aechmea 'Maya' in response to elevated $\mathrm{CO}_{2}$. Annals of Botany 102, 389-397.

Chen L-S, Nose A (2000) Characteristics of adenosinetriphosphatase and inorganic pyrophosphatase in tonoplasts isolated from three CAM species, Ananas comosus, Kalanchoё pinnata and K. daigremontiana. Plant Production Science 3, 24-31.

Chia DW, Yoder TJ, Reiter W-D, Gibson SI (2000) Fumaric acid: an overlooked form of fixed carbon in Arabidopsis and other plant species. Planta 211, 743-751.

Coutinho LM (1963) Algumas informações sôbre a ocorrência do "Efeito de De Saussure" em epífitas e herbáceas terrestres da mata pluvial. Boletim n ${ }^{\circ} 288$, Faculdade de Filosofia, Ciências e Letras da Universidade de São Paulo - Botânica 20, 83-98. 
1 Crayn DM, Winter K, Smith JAC (2004) Multiple origins of crassulacean acid metabolism and the epiphytic habit in the Neotropical family Bromeliaceae. Proceedings of the National Academy of Sciences USA 101, 3703-3708.

Crayn DM, Winter K, Schulte K, Smith JAC (2015) Photosynthetic pathways in Bromeliaceae: phylogenetic and ecological significance of CAM and $\mathrm{C}_{3}$ based on carbon isotope ratios for 1893 species. Botanical Journal of the Linnean Society 178, 169-221.

Cushman JC (2001) Crassulacean acid metabolism: a plastic photosynthetic adaptation to arid environments. Plant Physiology 127, 1439-1448.

Givnish TJ, Sytsma KJ, Smith JF, Hahn WJ, Benzing DH, Burkhardt EM (1997) Molecular evolution and adaptive radiation in Brocchinia (Bromeliaceae: Pitcairnioideae) atop tepuis of the Guayana Shield. In 'Molecular evolution and adaptive radiation.' (Eds TJ Givnish, KJ Sytsma) pp. 259-311. (Cambridge University Press: Cambridge)

Givnish TJ, Barfuss MJH, Van Ee B, Riina R, Schulte K, Horres R, Gonsiska PA, Jabaily RS, Crayn DM, Smith JAC, Winter K, Brown GK, Evans TM, Holst BK, Luther H, Till W, Zizka G, Berry PE, Sytsma KJ (2011) Phylogeny, adaptive radiation, and historical biogeography in Bromeliaceae: insights from an eight- locus plastid phylogeny. American Journal of Botany 98, 872-895.

Hafke JB, Hafke Y, Smith JAC, Lüttge U, Thiel G (2003) Vacuolar malate uptake is mediated by an anion-selective inward rectifier. The Plant Journal 35, 116-128.

Holtum JAM, Smith JAC, Neuhaus HE (2005) Intracellular transport and pathways of carbon flow in plants with crassulacean acid metabolism. Functional Plant Biology 32, 429-449.

Kenyon WH, Severson RF, Black CC Jr (1985) Maintenance carbon cycle in Crassulacean acid metabolism plant leaves. Plant Physiology 77, 183-189.

Kluge M, Ting IP (1978) 'Crassulacean acid metabolism: analysis of an ecological adaptation.' (Springer: Berlin)

Kornas A, Fischer-Schlieb E, Lüttge U, Miszalski Z (2009) Adaptation of the obligate CAM plant Clusia alata to light stress: metabolic responses. Journal of Plant Physiology 166, 1914-1922.

Lüttge U, Pfeifer T, Fischer-Schliebs E, Ratajczak (2000) The role of vacuolar malatetransport capacity in crassulacean acid metabolism and nitrate nutrition. Higher 
malate-transport capacity in the ice plant after crassulacean acid metabolisminduction and in tobacco under nitrate nutrition. Plant Physiology 124, 1335-1347.

Lüttge U (2000) The tonoplast functioning as the master switch for circadian regulation of crassulacean acid metabolism. Planta 211, 761-769.

Martin CE (1994) Physiological ecology of the Bromeliaceae. The Botanical Review 60, $1-82$.

Maxwell C, Griffiths H, Borland AM, Broadmeadow MSJ, McDavid C (1992)

Photoinhibitory responses of Guzmania monostachia during the dry season in Trinidad maintain photochemical integrity under adverse conditions. Plant, Cell and Environment 15, 37-47.

Maxwell C, Griffiths H, Young AJ (1994) Photosynthetic acclimation to light regime and water stress by the $\mathrm{C}_{3}$-CAM epiphyte Guzmania monostachia: gas exchange characteristics, photochemical efficiency and the xanthophyll cycle. Functional Ecology 8, 746-754.

McRae SR, Christopher JT, Smith JAC, Holtum JAM (2002) Sucrose transport across the vacuolar membrane of Ananas comosus. Functional Plant Biology 29, 717-724.

Medina E (1974) Dark $\mathrm{CO}_{2}$ fixation, habitat preference and evolution within the Bromeliaceae. Evolution 28, 677-686.

Medina E, Olivares E, Diaz M (1986) Water stress and light intensity effects on growth and nocturnal acid accumulation in a terrestrial CAM bromeliad (Bromelia humilis Jacq.) under natural conditions. Oecologia 70, 441-446.

Mertens E (1991) Pyrophosphate-dependent phosphofructokinase, an anaerobic glycolytic enzyme? FEBS Letters 285: 1-5.

Mez C (1904) Physiologische Bromeliaceen-Studien. I. Die Wasser-Ökonomie der extrem atmosphärischen Tillandsien. Jahrbücher für wissenschaftliche Botanik $\mathbf{4 0}$, $157-229$.

Ming R, Van Buren R, Wai CM, Tang H, Schatz MC, Bowers JE, Lyons E, Wang M-L, Chen J, Biggers E. et al. (2015) The pineapple genome and the evolution of CAM photosynthesis. Nature Genetics 47, 1435-1442.

Moore GA, Dewald MG, Evans MH (1992) Micropropagation of pineapple (Ananas comosus L.). In 'Biotechnology in agriculture and forestry. High-Tech and micropropagation II.' (Ed. YPS Bajaj) pp. 460-470. (Springer: Berlin) 
1 Neales TF, Patterson AA, Hartney VJ (1968) Physiological adaptation to drought in the carbon assimilation and water loss of xerophytes. Nature 219, 469-472.

Pereira PN, Purgatto E, Mercier H (2013) Spatial division of phosphoenolpyruvate carboxylase and nitrate reductase activity and its regulation by cytokinins in CAMinduced leaves of Guzmania monostachia (Bromeliaceae). Journal of Plant Physiology 170, 1067-1074.

Pollack JD, Williams MV (1986) PPi-dependent phosphofructotransferase (phosphofructikinase) activity in the Mollicutes (Mycoplasma) Acholeplasma laidlawii. Journal of Bacteriology 165, 53-60.

Sideris CP, Young HY, Chung HHQ (1948) Diurnal changes and growth rates as associated with ascorbic acid, titratable acidity, carbohydrate and nitrogenous fractions in the leaves of Ananas comosus (L.) Merr. Plant Physiology 23, 38-69.

Silvera K, Lasso E (2016) Ecophysiology and crassulacean acid metabolism of tropical epiphytes. In: 'Tropical tree physiology: adaptations and responses in a changing environment.' (Eds G Goldstein, LS Santiago) pp. 25-43. (Springer: New York)

Smith JAC, Griffiths H, Lüttge U (1986) Comparative ecophysiology of CAM and $\mathrm{C}_{3}$ bromeliads. I. The ecology of the Bromeliaceae in Trinidad. Plant, Cell and Environment 9, 359-376.

Smith JAC (1989) Epiphytic bromeliads. In 'Vascular plant as epiphytes: evolution and ecophysiology.' (Ed. U Lüttge) pp. 109-138. (Springer: Berlin)

Smith, LB, Till W (1998) Bromeliaceae. In 'The families and genera of vascular plants. Vol. 4: Alismatanae and Commelinanae (except Graminae).' (Ed. K Kubitzki) pp. 74-99. (Springer: Berlin)

Struve I, Lüttge U (1987) Characteristics of $\mathrm{MgATP}^{2-}$-dependent electrogenic proton transport in tonoplast vesicles of the facultative crassulacean acid metabolism plant Mesembryanthemum crystallinum L. Planta 170, 111-120.

White PJ, Smith JAC (1989) Proton and anion transport at the tonoplast in crassulaceanacid-metabolism plants: specificity of the malate-influx system in Kalanchoë daigremontiana. Planta 179, 265-274.

White PJ, Marshall J, Smith JAC (1990) Substrate kinetics of the tonoplast $\mathrm{H}^{+}$translocating inorganic pyrophosphatase and its activation by free $\mathrm{Mg}^{2+}$. Plant Physiology 93, 1063-1070. 
1 Winter K, Smith JAC (1996) An introduction to crassulacean acid metabolism:

2 biochemical principles and ecological diversity. In 'Crassulacean acid metabolism:

3 biochemistry, ecophysiology and evolution.' (Eds K Winter K, JAC Smith) pp. 1-13.

$4 \quad$ (Springer: Berlin)

5

6

7

8

9

10

11

12

13

14

15

16

17 

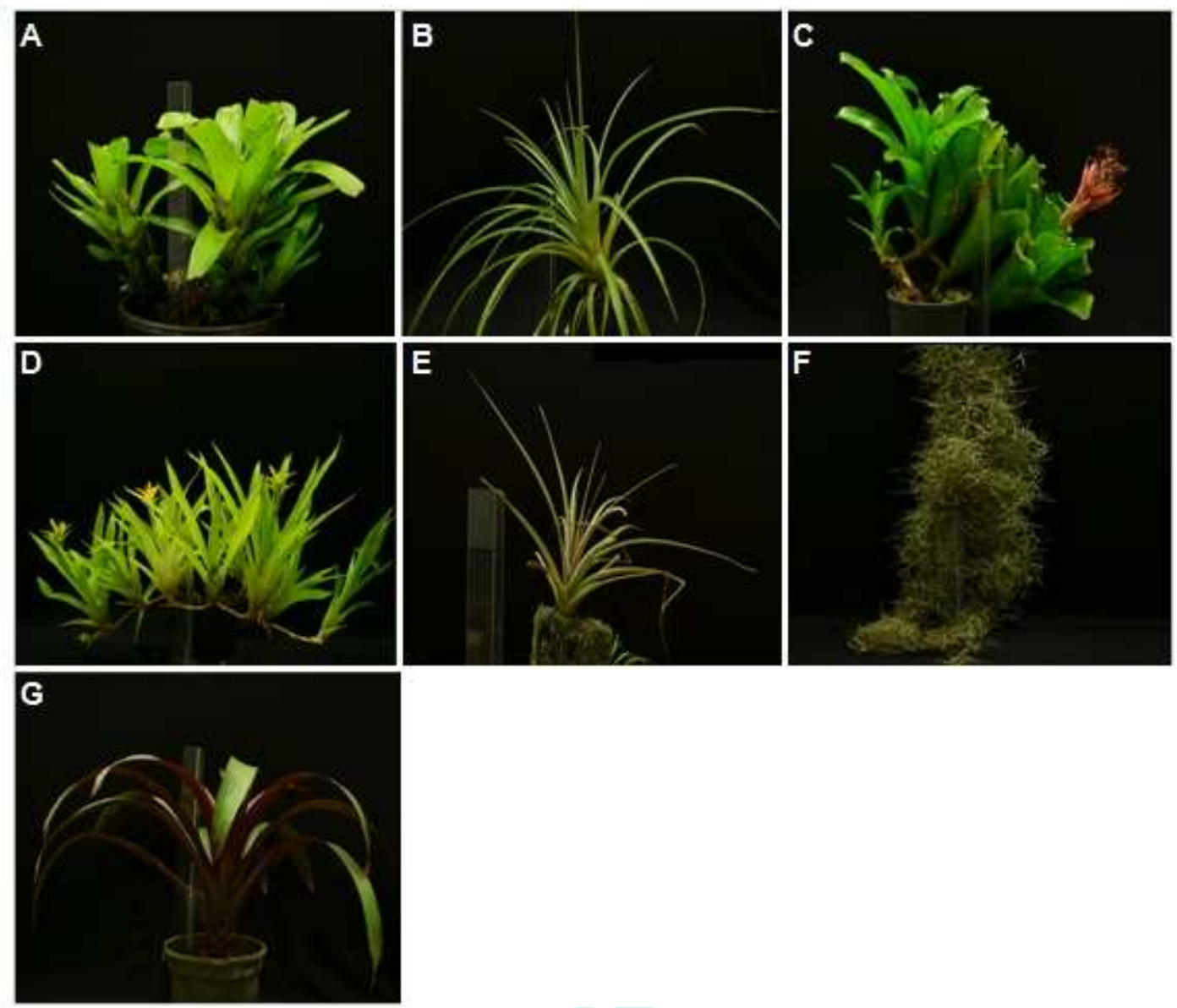

2 Fig. 1 The seven bromeliad species used in these experiments: (A) Aechmea nudicaulis;

3 (B) Ananas comosus; (C) Billbergia pyramidalis; (D) Nidularium billbergioides; (E)

$4 \quad$ Tillandsia pohliana; (F) Tillandsia usneoides; (G) Vriesea sucrei.

6 
1 Table 1. Initial rates of ATP-dependent proton transport into isolated tonoplast 2 vesicles from leaves of seven species bromeliads.

3 Proton transport was measured as the initial rate of quinacrine-fluorescence quenching

4 in the presence of $50 \mathrm{mM}$ fumarate following addition of $3 \mathrm{mM}$ ATP to the suspension

5 of tonoplast vesicles as described in Materials and methods. Rates of proton transport

6 were quantified as $\%$ relative fluorescence quenching $\min ^{-1} \mathrm{mg}$ protein ${ }^{-1}$.

7 Measurements were made in the presence of inhibitors of vacuolar $\mathrm{H}^{+}$-ATPase $(50 \mathrm{mM}$

$\left.8 \mathrm{KNO}_{3}\right)$ or non-vacuolar $\mathrm{H}^{+}$-ATPases $\left(0.1 \mathrm{mM} \mathrm{NaN}_{3}\right.$ plus $\left.0.1 \mathrm{mM} \mathrm{Na}_{3} \mathrm{VO}_{4}\right)$ in

9 comparison with the control (no inhibitors). Results are expressed as means ( \pm s.d.) for

10 three independent preparations. Values in parentheses give the percentage inhibition

11 relative to the control for each species; asterisks indicate significant differences between

12 each inhibitor $\left(\mathrm{KNO}_{3}\right.$ or $\left.\mathrm{NaN}_{3}+\mathrm{NaVO}_{3}\right)$ and the control within a species by Student's

$13 t$-test at $5 \%$ significance level.

\section{Specific activity (\% quench $\mathrm{min}^{-1} \mathrm{mg}_{\text {protein }}{ }^{-1}$ ) (inhibition relative to control)}

\begin{tabular}{lccc}
\hline Species & Control & $+\mathrm{KNO}_{3}$ & $\mathrm{NaN}_{3}+\mathrm{Na}_{4} \mathrm{VO}_{3}$ \\
\hline Aechmea nudicaulis & $1074 \pm 2$ & $604 \pm 8$ & $829 \pm 9$ \\
\hline Ananas comosus & & $(44 \%)^{*}$ & $(23 \%)^{*}$ \\
\hline Billbergia pyramidalis & $627 \pm 6$ & $140 \pm 7$ & $463 \pm 9$ \\
& & $(78 \%)^{*}$ & $(26 \%)^{*}$ \\
\hline Nidularium billbergioides & $546 \pm 5$ & $675 \pm 4$ & $1146 \pm 3$ \\
& & $(44 \%)^{*}$ & $(5 \%)^{*}$ \\
\hline Tillandsia pohliana & $291 \pm 7$ & $431 \pm 9$ \\
& $1045 \pm 9$ & $(47 \%)^{*}$ & $(21 \%)^{*}$ \\
\hline Tillandsia usneoides & & $(42 \%)^{*}$ & $(25 \%)^{*}$ \\
\hline Vriesea sucrei & $432 \pm 1$ & $114 \pm 3$ & $310 \pm 3$ \\
\hline
\end{tabular}


1 Table 2. Initial rates of ATP-dependent proton transport into isolated tonoplast

2

3

4

5

6

7

8

\begin{tabular}{|c|c|c|c|c|}
\hline Species & Fumarate & Malate & Citrate & Control \\
\hline Aechmea nudicaulis & $2235 \pm 19$ & $512 \pm 19$ & $116 \pm 10$ & $465 \pm 15$ \\
\hline Ananas comosus & $2573 \pm 33$ & $503 \pm 3$ & $37 \pm 1$ & $112 \pm 1$ \\
\hline Billbergia pyramidalis & $3542 \pm 1$ & $632 \pm 33$ & $208 \pm 17$ & $577 \pm 4$ \\
\hline Nidularium billbergioides & $1983 \pm 9$ & $339 \pm 8$ & $44 \pm 8$ & $266 \pm 9$ \\
\hline Tillandsia pohliana & $1635 \pm 22$ & $444 \pm 6$ & $114 \pm 12$ & $336 \pm 27$ \\
\hline Tillandsia usneoides & $271 \pm 10$ & $65 \pm 3$ & $33 \pm 2$ & $54 \pm 9$ \\
\hline Vriesea sucrei & $89 \pm 4$ & $25 \pm 3$ & $46 \pm 4$ & $27 \pm 2$ \\
\hline
\end{tabular}


1 Table 3. Initial rates of PPi-dependent proton transport into isolated tonoplast 2 vesicles from leaves of seven species of bromeliads in dependence on the balancing 3 carboxylate anion.

4 Proton transport was measured as described in Table 1 in the presence of three different 5 carboxylate anions (fumarate, malate, or citrate, each supplied as their BTP-salt at 50

$6 \mathrm{mM}$ ) in comparison with the control (no added carboxylate anion). Rates of proton

7 transport were quantified as $\%$ relative fluorescence quenching $\min ^{-1} \mathrm{mg} \mathrm{protein}^{-1}$;

8 values are expressed as means ( \pm s.d.) for three independent preparations. Different

9 capital letters indicate values that were significantly different among species using the 10 same anion (Tukey-Kramer test; $P<0.05$ ). Different lower case letters indicate values

11 that were significantly different among different carboxylate anions in the same species

12 (Tukey-Kramer test; $P<0.05$ ).

\begin{tabular}{|c|c|c|c|c|}
\hline & & \multicolumn{3}{|c|}{ Specific activity (\%. $\min ^{-1}$ quench $\mathrm{mg}$ protein $\left.{ }^{-1}\right)$} \\
\hline Species & Fumarate & Malate & Citrate & Control \\
\hline Aechmea nudicaulis & $627 \pm 4$ & $668 \pm 38$ & $99 \pm 6$ & $194 \pm 20$ \\
\hline Ananas comosus & $266 \pm 0.5$ & $197 \pm 1$ & $37 \pm 2$ & $49 \pm 1$ \\
\hline Billbergia pyramidalis & $848 \pm 19$ & $729 \pm 10$ & $3 \pm 0.2$ & $327 \pm 18$ \\
\hline Nidularium billbergioides & $383 \pm 8$ & $407 \pm 8$ & $1 \pm 0.2$ & $194 \pm 8$ \\
\hline Tillandsia pohliana & $345 \pm 14$ & $48 \pm 5$ & $73 \pm 4$ & $39 \pm 3$ \\
\hline Tillandsia usneoides & $13 \pm 1$ & $13 \pm 2$ & $31 \pm 3$ & $49 \pm 2$ \\
\hline Vriesea sucrei & $25 \pm 3$ & $77 \pm 6$ & $26 \pm 1$ & $21 \pm 3$ \\
\hline
\end{tabular}



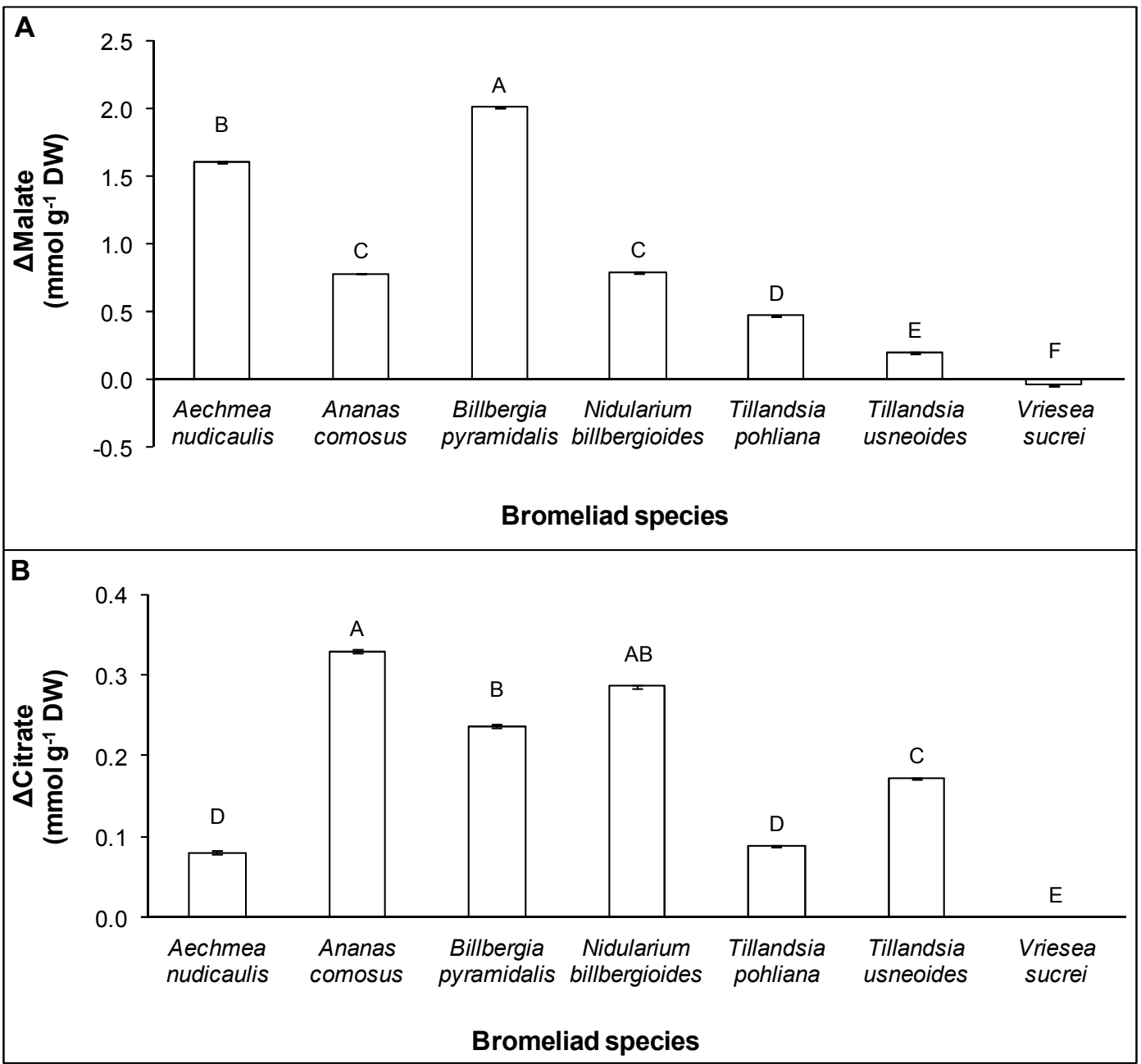

2 Fig. 2. Nocturnal accumulation of (A) malate and (B) citrate in the leaves of seven

3 bromeliad species. Values for $\Delta$ malate and $\Delta$ citrate were calculated as the difference in

4 malate and citrate concentration, respectively, in samples harvested at dawn minus those

5 harvested at dusk as described in Materials and methods. Values are means ( \pm s.d.) of 3

6 samples, with each sample consisting of material pooled from three individual plants.

7 Different letters indicate values that were significantly different among bromeliad

8 species (Tukey-Kramer test; $P<0.05$ ). DW = dry weight. 


\section{Supplementary Material}

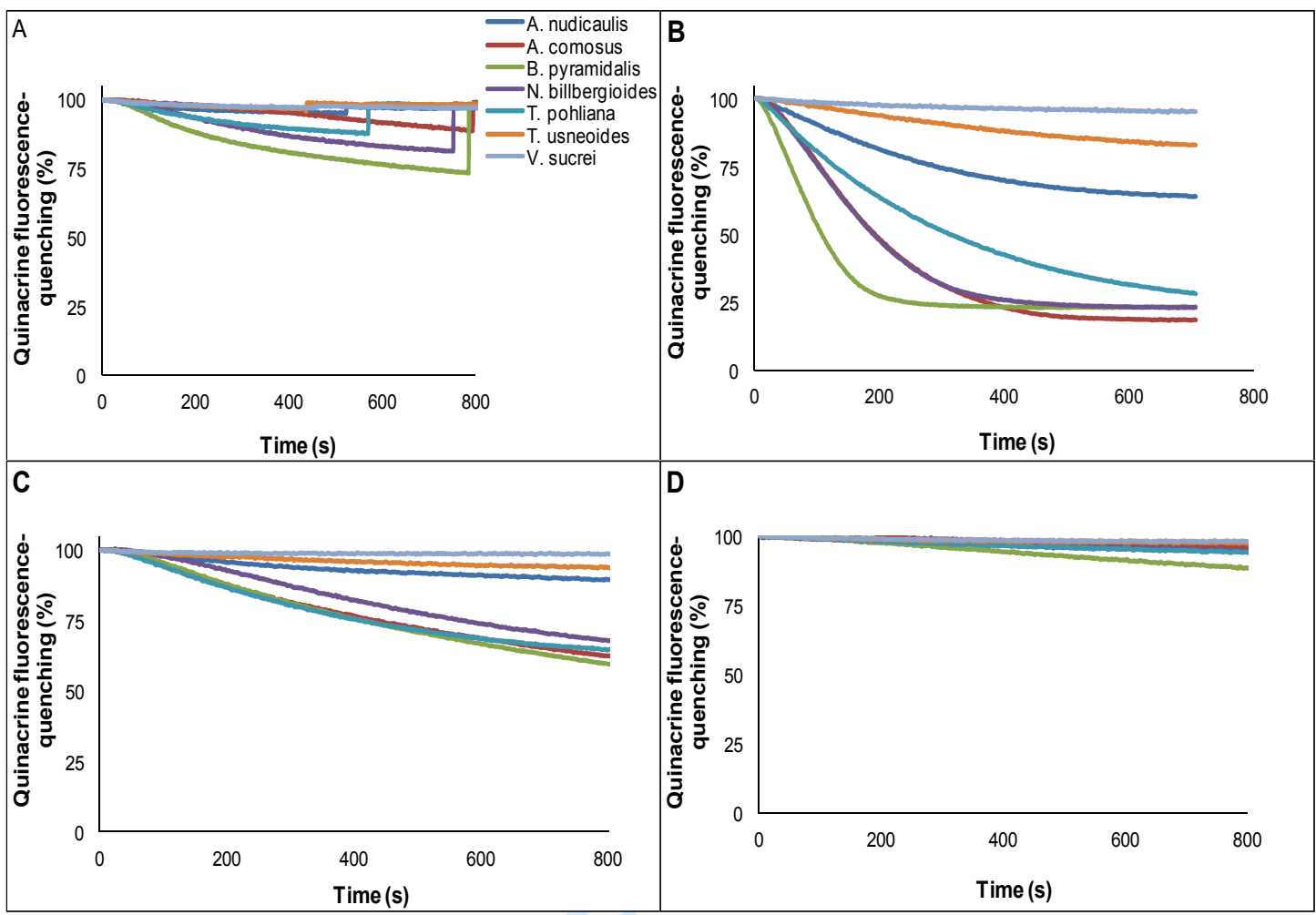

3 Supplementary Fig. 1. ATP-dependent proton transport into isolated tonoplast

4 vesicles monitored by quinacrine-fluorescence quenching (expressed as a percentage of

5 the starting value) in (A) control conditions (no added carboxylate anion), or in the

6 presence of (B) $50 \mathrm{mM}$ fumarate, (C) $50 \mathrm{mM}$ malate, or (D) $50 \mathrm{mM}$ citrate. Tonoplast

7 vesicles were isolated as described in Materials and methods from leaves of Aechmea

8 nudicaulis, Ananas comosus, Billbergia pyramidalis, Nidularium billbergioides,

9 Tillandsia pohliana, T. usneoides and Vriesea sucrei. Proton transport was initiated by

10 the addition of ATP $(3.0 \mathrm{mM})$ at the start of the time-course. In A, $2.0 \mathrm{mM} \mathrm{NH}_{4}{ }^{+}$was

11 added as an uncoupler at a time between $400 \mathrm{~s}$ and $800 \mathrm{~s}$ (depending on the species) to

12 demonstrate abolition of the $\mathrm{pH}$ gradient established by ATP-dependent proton

13 transport. Results are from one experiment representative of a total of three. 


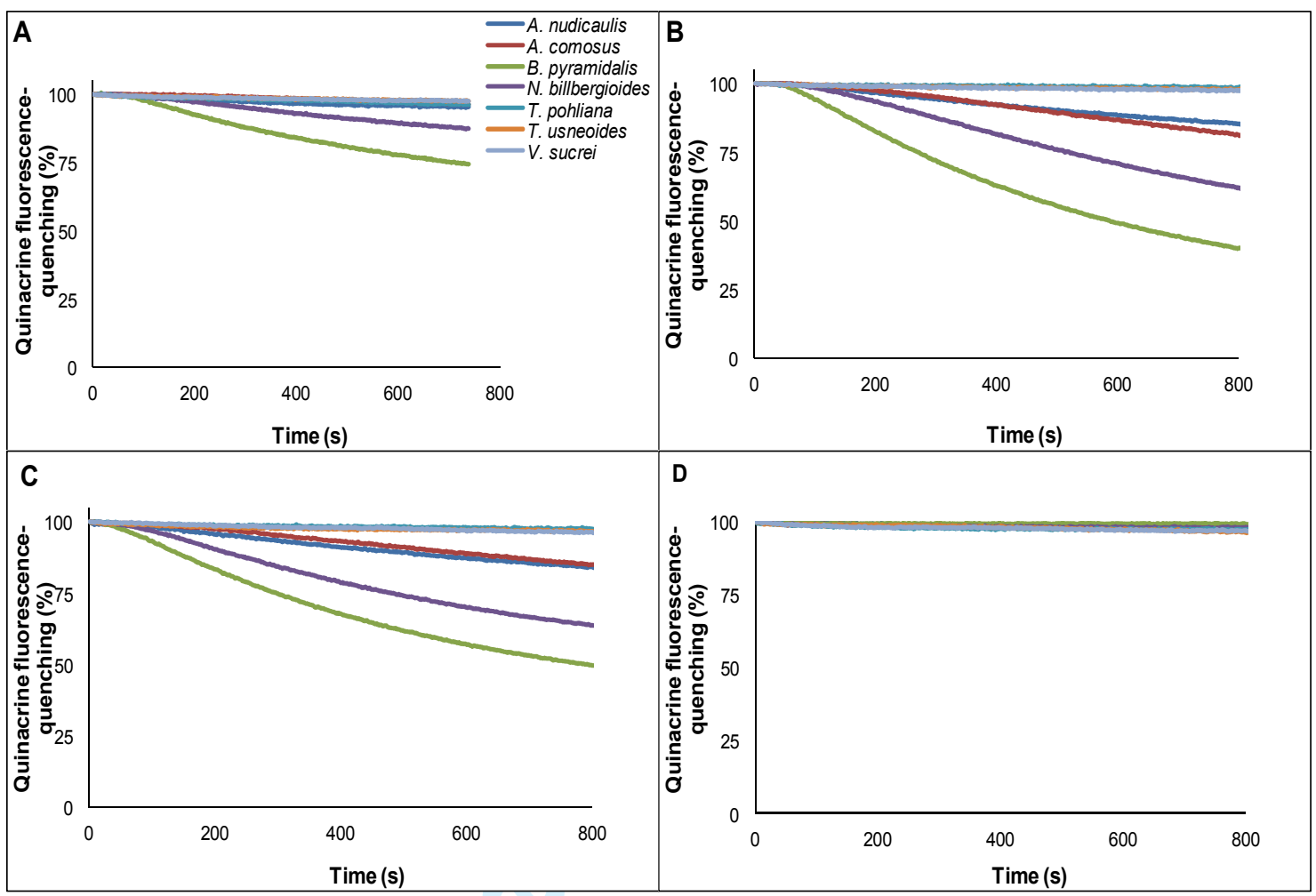

2 Supplementary Fig. 2. PPi-dependent proton transport into isolated tonoplast vesilces

3 monitored by quinacrine-fluorescence quenching (expressed as a percentage of the

4 starting value) in (A) control conditions (no added carboxylate anion), or in presence of

5 (B) $50 \mathrm{mM}$ fumarate, (C) $50 \mathrm{mM}$ malate, or (D) $50 \mathrm{mM}$ citrate (D). Tonoplast vesicles

6 were isolated as described in Materials and methods from leaves of Aechmea

7 nudicaulis, Ananas comosus, Billbergia pyramidalis, Nidularium billbergioides,

8 Tillandsia pohliana, T. usneoides and Vriesea sucrei. Proton transport was initiated by

9 the addition of PPi $(3.0 \mathrm{mM})$ at the start of the time-course. Results are from one

10 experiment representative of a total of three. 